\title{
Las fórmulas narrativas en cine y literatura: una propuesta paradigmática
}

The narrative formulas in cinema and literature:

\author{
a paradigmatic proposal
}

\section{Lauro Zavala}

Universidad Autónoma Metropolitana Xochimilco, México.

zavala38ahotmail.com

\section{Resumen}

En este trabajo retomo la tradición académica orientada a plantear la existencia de estrategias narrativas comunes a todos los soportes semióticos. Propongo la creación de un sistema de fórmulas narrativas que permiten precisar la naturaleza estructural de estrategias narrativas fundamentales, como el suspenso, la sorpresa, la transferencia de culpa y la narrativa conjetural, así como las estrategias distintivas del inicio y el final de naturaleza clásica, moderna y posmoderna. Para el análisis se utilizan películas de Alfred Hitchcock y novelas y cuentos del siglo XX.

\section{Palabras clave}

Fórmulas Narrativas, Teoría Incoativa, Teoría Terminativa, Cine, Literatura.

\begin{abstract}
This paper presents a general overview of the narratological tradition in order to pose the existence of narrative strategies that are common to every narration. Terminative theory has received much more attention than inchoative theory. This paper presents a system of narrative formulas which are useful for studying the structural nature of fundamental narrative strategies, such as narrative suspense, surprise, guilt transference, and conjectural fiction, as well as the structural strategies of classic, modern, and postmodern beginnings and endings. The examples belong in Alfred Hitchcock's films and 20th century novels and short stories.
\end{abstract}

\section{Keywords}

Narrative Formulas, Inchoative Theory, Terminative Theory, Film, Literature. 


\section{Introducción}

El objetivo de este trabajo es proponer la creación de un sistema de fórmulas narrativas de carácter universal que facilite el análisis de las estrategias estructurales comunes a todos los soportes semióticos (cine, literatura, narrativa gráfica, periodismo, etc.). Estas fórmulas serán ejemplificadas con textos canónicos de la tradición literaria y cinematográfica.

La estrategia utilizada para elaborar estas fórmulas ha consistido en estudiar los conceptos clave de la tradición narratológica, en particular en la teoría de la novela, la teoría del cuento y la teoría del cine, y al estudiar la teoría incoativa les decir, la teoría del inicio narrativol y la teoría terminativa (es decir, la teoría del final narrativol enmarcadas todas ellas en la aproximación paradigmática les decir, en la distinción entre narrativa clásica, moderna y posmodernal. De esta manera, estas fórmulas son útiles para analizar cualquier material narrativo en cualquier formato o soporte.

Existen al menos tres tipos de razones disciplinarias e interdisciplinarias para justificar la creación de estas fórmulas: sus antecedentes lógicos en la semiótica, los orígenes lingüísticos de la semiología, y la exigencia de legitimación de toda aproximación interdisciplinaria. En el caso de la semiótica, sus antecedentes lógicos son evidentes en el trabajo del creador de esta disciplina, Charles S. Peirce, pues él mismo era un profesor de filosofía especializado en la argumentación lógica, si bien su trabajo académico era "notablemente polifacético" (T. Sebeok \& J. Sebeok, 1979: 87). En el caso de la lingüística estructural, ésta se encuentra en la raíz metodológica de gran parte de la narratología clásica, con lo cual el estructuralismo se ha convertido en la teoría lingüística más productiva en el estudio de la narrativa (Valles-Mingo, 2009: 21). Y la creación de fórmulas en el campo de las humanidades y las ciencias sociales Icomo ocurre en el psicoanálisis lacaniano, la antropología estructural o la teoría del diseño), aunque no ha estado exenta de polémica, responde a una exigencia de legitimación cuando estas disciplinas adoptan un carácter interdisciplinario (Klein, 1996: 128).

Al mismo tiempo, la producción de fórmulas en la narratología cumple al menos tres objetivos disciplinarios: utilidad metodológica, alcance universal y aplicabilidad práctica. La utilidad metodológica de crear fórmulas narrativas es evidente por la necesidad de contar con modelos de análisis que tengan la mayor precisión posible. Su alcance universal consiste en que formalizan una serie de estrategias que están presentes en cualquier material narrativo. Y su aplicabilidad práctica consiste en la posibilidad de su empleo en los procesos de producción narrativa, es decir, en la elaboración de películas, novelas, cuentos, videojuegos y otras formas de narración.

\section{Antecedentes narratológicos}

La tradición narratológica se sustenta en la elaboración de sistemas conceptuales de utilidad universal. Esta tradición se remonta a los primeros trabajos del formalismo ruso. En particular, fue Viktor Sklovski quien propuso en 1913 el concepto de ostrannenie o extrañamiento para distinguir el rasgo formal que distingue cualquier obra de arte moderno, y este concepto fundacional sigue siendo pertinente para el estudio de las formas más experimentales de narrativa contemporánea (Van den Oever, 2013: 12). En 1938, Bertolt Brecht propone en la teoría dramática el concepto de Verfremdung o distanciamiento, como una estrategia conducente a la toma de conciencia ideológica a través del estímulo a la capacidad de asombro de los espectadores.

El primer sistema de fórmulas narrativas fue propuesto en 1928 por Vladimir Propp en su Morfología del relato, donde el investigador ruso se aparta de la tradición genética les decir, el estudio sobre los orígenes del cuento de tradición oral), dominante en ese momento, y propone una aproximación sincrónica (Propp, 1928: 17). Medio siglo después, estas fórmulas fueron utilizadas para estudiar la evolución estructural del western clásico, en sus variantes modernas, lo cual es un reflejo del universo ideológico de sus espectadores (Wright, 1976: 27). Si bien éste es un terreno de la narratología alejado de la literatura, es un antecedente importante en la búsqueda de un sistema de fórmulas de carácter universal.

En 1928, Boris Tomachevski, en su Teoría de la literatura, propuso la distinción originaria entre historia y discurso, es decir, entre el contenido y la estructura de la secuencia narrativa, distinción apoyada en la construcción sintáctica y la existencia de unidades estructurales en todo material narrativo (Tomachevski, 1928: 64). En 1935 Sergei 
Eisenstein propone, en su teoría del montaje cinematográfico, la distinción entre el orden lógico (vorschlag) y el orden cronológico (nachslag) de toda narración, lo que constituye una contribución notable para una definición universal de la narración.

Durante la segunda mitad de siglo XX la narratología estructural francesa produjo notables propuestas teóricas. En 1966 Algirdas J. Greimas propone, entre muchos otros conceptos, el de isotopía narrativa, que tiene un carácter semántico, es decir, de origen lingüístico. Poco después, Gérard Genette establece la distinción entre orden, duración y frecuencia en el estudio del tiempo narrativo (Gene-tte, 1972: 33). Por su parte, en 1958 Roland Barthes estableció la distinción entre nudos y catálisis en toda narración: mientras los nudos son imprescindibles para la existencia de un relato, en cambio las catálisis entre un nudo y otro cumplen una función conectiva. $Y$ pocos años después, el mismo Barthes señaló la existencia de lo que llamó las "estrategias de seducción narrativa" (Barthes, 1966: 175), tales como suspensión, dilatación, alteración, suspensión y bloqueo de la solución al enigma narrativo, todos los cuales mantienen la atención del lector o espectador.

En el nuevo siglo se han producido varios compendios panorámicos sobre el estado de la narratología. En 1999, Suzanne Keen publica su Narrative Form, y ese mismo año aparece la Lingüística de textos narrativos, de Jean-Michel Adam y ClaraUbaldina Lorda. En 2001 se publicó la traducción del holandés del Handbook of Narrative Analysis, de Luc Hermann y Bart Vervaeck, y en 2009 se tradujo otro trabajo de origen holandés, Film Narratology, de Peter Verstratten. En ambos se retoman las propuestas que habían sido elaboradas en 1995 por Francois Jost y André Gaudreault en su Cine y narratología.

Como se puede observar, hasta el momento no se ha propuesto un sistema de fórmulas narrativas que permitan precisar la naturaleza estructural de cualquier producto narrativo. Las fórmulas que presento a continuación se derivan de la teoría de la novela (para el estudio del suspenso y la sorpresa narrativa); la teoría del cuento (para estudiar la narrativa conjetural); la teoría del cine (para el estudio de la transferencia de culpa), y la teoría incoativa (para el estudio del inicio y el final de toda narración).

\section{Primeras fórmulas narrativas}

Un primer grupo de fórmulas narrativas pertenece a lo que se puede considerar como estrategias estructurales de carácter general: el suspenso, la sorpresa, la transferencia de culpa y la narrativa policiaca. En lo que sigue presento estas fórmulas y su ejemplificación en cine y literatura.

En el suspenso narrativo, lo que se suspende es el momento de revelación de la verdad narrativa para el protagonista, quien durante el relato ignora esta verdad, y con frecuencia también ignora que es víctima de un engaño. Se trata de una verdad que determina el sentido de la narración misma, como ocurre con la verdadera identidad de un criminal o la revelación de un secreto de familia o cualquier otra verdad sustancial para la existencia misma de la narración. Suspender la revelación de una verdad, que generalmente se mantiene en secreto, no significa cancelar esta revelación, sino que el descubrimiento de esta verdad se pospone (es decir, se suspende) para ser revelada al protagonista en un momento específico del relato, que generalmente coincide con el final. A esta revelación final se le llama epifanía del personaje.

En otras palabras, el suspenso narrativo consiste en que el espectador (o lector) sabe algo que el personaje no sabe. Este principio narrativo, propio de la narración clásica, da lugar a la primera de las fórmulas narrativas, precisamente la Fórmula del Suspenso Narrativo: (E s, P -s), que se lee de esta manera: el Espectador (E), sabe algo (s) que el Personaje (P) no sabe (-s). La instancia narrativa la la que podríamos considerar como el autor implícito del relato) crea así una especie de complicidad con el lector o espectador, al confiarle un secreto que se mantiene oculto para el personaje (o personajes).

Para Roland Barthes, el suspenso narrativo es la estrategia más importante del proceso de seducción narrativa que establece la narración realista decimonónica, como lo demostró él mismo en el estudio sobre la novela Sarrazine de Balzac (Barthes, 1970: 28). El suspenso narrativo ya está presente en la tradición clásica (como en la trama de Edipo Rey, de Sófocles) y define la estructura narrativa del cine de géneros lespecialmente en los casos del cine fantástico, policiaco, terror y ciencia ficción). En el caso de Edipo Rey, los espectadores sabemos que el protagonista hace el amor con su madre y que mata a su padre, pero él sólo lo sabrá más adelante, y es este conocimiento lo que provocará la tragedia. 
En algunas películas canónicas del cine de crímenes, como La soga, Blackmail o Sabotaje ldirigidas todas por Alfred Hitchcock), los primeros minutos muestran al espectador, sobre la pantalla, quién o quiénes cometen un crimen de manera deliberada y en ocasiones con una minuciosa planeación. Sin embargo, los demás personajes ignoran este hecho durante toda la trama, y en ocasiones, como en Blackmail, lo ignoran de manera definitiva.

En la película Espera la obscuridad (1967), la protagonista es ciega y recibe la inesperada visita de varios desconocidos en su propio departamento, que la tratan de engañar aprovechando su condición. Los espectadores sabemos cosas que ella ignora lcomo los móviles que tienen estos personajes) y vemos cosas que ella no puede ver, todo lo cual crea un suspenso permanente.

En Marnie, la ladrona (1964) vemos a la protagonista entrar a una oficina, fuera del horario de trabajo, y robar un documento importante. Cuando ella se dispone a salir de la oficina, la cámara se desplaza a la izquierda, y mientras la vemos a ella en la mitad derecha de la pantalla, vemos en la mitad izquierda a una mujer que trapea el suelo y que está de espaldas a nosotros. En ese momento, la protagonista deja caer un objeto que hace mucho ruido y sólo después sabremos que eso no importa porque la mujer de la limpieza es sorda.

El suspenso narrativo siempre está acompañado por la sorpresa narrativa. En este caso, es el narrador quien sabe algo que el espectador (o lector) no sabe. Este recurso puede dar lugar a la Fórmula de la Sorpresa: ( $\mathrm{N}$ s, E -s), que se lee de esta manera: el Narrador (N), sabe algo (s) que el Espectador (E) no sabe (-s). El espectador puede saber que algo va a ocurrir, pero ignora qué será o cuándo va a ocurrir. El espectador será sorprendido por el narrador lo la instancia narrativa, en generall.

En La soga, aunque sabemos quién cometió el crimen del estudiante (porque vimos cometer este crimen en el primer minuto de la película), nos sorprenderá saber quién lo descubre y cómo logró este descubrimiento. En Marnie, la ladrona nos sorprende descubrir, en una conversación de los personajes, que la mujer de la limpieza es sorda.

Pero la sorpresa del lector o espectador no siempre ocurre cuando hay suspenso. Gran parte de la atracción que ejerce la narración policiaca en sus lectores o espectadores consiste en conocer cómo el investigador privado descubre un secreto que nosotros no pudimos descubrir, aunque teníamos acceso a todas las claves. Esta revelación es una sorpresa para el lector o espectador. La sorpresa es el elemento central del cine de terror, donde continuamente se crean nuevas estrategias de sorpresa, pues este género se define por la existencia de toda clase de amenazas que con frecuencia ignoramos dónde, cuándo o por qué se originan.

Las películas dirigidas por Alfred Hitchcock en un lapso de 48 años (de 1926 a 1974) son un referente imprescindible al estudiar el suspenso narrativo (que oculta una verdad al personaje) y la sorpresa (que oculta una verdad al espectador). En estas películas, con frecuencia el suspenso está construido a partir de una transferencia de culpa. La Fórmula de la Transferencia de Culpa (P c (a), E c (b) ) significa que los Personajes (P) creen que alguien (a) es culpable de un crimen (c), pero el Espectador (E) sabe que el verdadero culpable (c) es otro (b).

Al inicio de Saboteador (1942) vemos a un hombre colocar una bomba en un edificio y ajustar el reloj para programar su explosión. Al día siguiente, a la hora del desayuno, este mismo hombre encuentra en la primera plana del periódico la noticia del estallido, y actúa frente a su esposa como si esta noticia lo sorprendiera. Pero nosotros sabemos que él es el culpable de este crimen. En Extraños en un tren (1951) conocemos el pacto que establecen dos desconocidos que se encuentran casualmente en un viaje de tren. Este pacto consiste, precisamente, en que cada uno de ellos cometerá un crimen que el otro desea cometer sin ser descubierto. Al ser una película de film noir encontramos distintos grados de ambigüedad moral en cada uno de estos personajes, lo que terminará provocando más de una transferencia de culpa.

En el relato policiaco, es decir, en la narrativa conjetural, el lector (o espectador) sabe que hay un crimen y conoce algunos elementos circunstanciales Icomo pueden ser la identidad de la víctima, el lugar y la hora del crimen), pero ignora con certeza quién lo cometió (en inglés whodunit = quién lo hizo). En esta clase de relato encontramos una verdad epifánica, es decir, una verdad que debe ser revelada al final de la historia. En la Fórmula del Whodunit ( $\mathrm{N} \mathrm{s}$ (c), E -s (c) ), el Narrador ( $N$ ) sabe (s) quién cometió el crimen (c), pero el Espectador (E) no lo sabe (-s), y tratará de saberlo durante el proceso de lectura. El relato policiaco pone en juego la capacidad de razonamiento abductivo del lector, es decir, su capacidad para elaborar hipótesis a partir de síntomas, huellas y sinécdoques (Eco, 1983: 275). 
La narración donde se plantea un enigma por resolver tiene antecedentes en Voltaire y otros escritores, pero fue Edgar Allan Poe quien elaboró sus reglas fundamentales, que son válidas para todos los textos de este género. Otros escritores de relatos policiacos han desarrollado estas reglas de manera más elaborada, como W. S. Van Dine, Ronald A. Knox, Jorge Luis Borges, Raymond Chandler y Patricia Highsmith (Zavala, 1995: 309-428). En todos los casos, el final suele presentar la revelación de la verdad epifánica que resuelve el enigma. Éste es el mecanismo narrativo que encontramos en los cuentos policiacos de Arthur Conan Doyle, Edgar Alan Poe y Bustos Domecq, y en las novelas de Agatha Christie, G. K. Chesterton y otros. Estas estrategias se ponen en juego en series televisivas de la década del 2000 como Dr. House Isobre la investigación médica) o Lie to Me (sobre la investigación del lenguaje corporall.

\section{El inicio y el final en la narrativa clásica}

En lo que sigue se presentan las fórmulas de los inicios y finales de tipo clásico, moderno y posmoderno. Aquí conviene recordar que el paradigma de lo clásico se refiere a todo aquello que es atemporal y convencional, y cuya efectividad es universal, mientras que lo moderno es todo aquello que se opone a lo clásico, es decir, que surge de una visión individual, y que en esa medida es único e irrepetible. En ese sentido, la narrativa clásica es la más accesible y didáctica (como es el caso del cine de géneros), mientras que la narrativa moderna es la más experimental y vanguardista, exigente y de difícil acceso. Mientras la narrativa clásica se apoya en la tradición, la narrativa moderna se apoya en la visión personal del autor. Mientras una narración clásica es estructuralmente similar a cualquier otra narración clásica, en cambio cada narración moderna, en términos estructurales, es distinta a cualquier otra narración.

Por su parte, la narrativa posmoderna es paradójica y tiende a ser irónica, pues consiste en la presencia simultánea de los rasgos clásicos y modernos en un mismo texto o en la presencia de simulacros de lo clásico o lo moderno. La simultaneidad lleva a utilizar estrategias como la hibridación genérica, y los simulacros llevan a utilizar recursos como la metaparodia, es decir, la parodia de rasgos genéricos. En términos generales, la narrativa posmoderna es una forma de recuperación extemporánea o reciclaje irónico de las convenciones de la narrativa clásica.

La teoría incoativa es la rama de la narratología que estudia el inicio narrativo. Y se apoya en los principios que sostienen la teoría terminativa, es decir, la rama de la narratología que estudia el final narrativo. En otras palabras, el estudio de las estrategias utilizadas para iniciar una narración se desprende del estudio de las estrategias utilizadas para terminar una narración. Ambas teorías son inseparables, de la misma manera que toda narración que termina es una narración que tiene un inicio. La narratología incoativa es un terreno estratégico para estudiar cualquier forma de narración. En lo que sigue propongo una serie de fórmulas derivadas de la tradición narratológica. Entre los trabajos más sobresalientes de la teoría incoativa es necesario mencionar los producidos por Frank Kermode (1986), Richard Neupert (1995), Marco Kunz (1997) y James MacDowell (2014).

\section{Fórmulas de incoativa clásica}

El inicio clásico de una historia consiste en pasar de un Plano General (PG) a un Primer Plano (PP) en términos de tiempo ( $t$ ) y espacio (e). Por lo tanto, la Fórmula del Inicio Clásico es (PG (t, e) $\rightarrow$ PP $(t, e)$ ). El Plano General (PG) es una visión panorámica, de conjunto, que permite conocer el contexto donde ocurrirá la historia y quiénes son los personajes que participan en ella. El Primer Plano (PP) es una perspectiva donde se observa un detalle, es decir, algo muy particular que podría no ser percibido con precisión al observar un Plano General. En otras palabras, el inicio clásico pasa de lo más general a lo más particular, en un movimiento narrativo que va del contexto general hasta llegar al texto particular. El inicio clásico suele estar acompañado por recursos narrativos tales como la catáfora explícita (cuando se anuncia aquello que va a ser narrado); la intriga de predestinación (cuando al empezar la historia se anuncia el final del re(ato), y el establecimiento del suspenso narrativo Icuando se establece una complicidad del narrador con el espectador al ofrecerle el conocimiento de algo que los personajes ignoran). El inicio clásico es característico de la novela realista, el cine de géneros y el cuento policiaco. 
Examinemos por un momento las primeras imágenes de la película Psicosis (Psycho, 1960), del director Alfred Hitchcock. Inmediatamente después de los créditos vemos la imagen panorámica de una ciudad observada desde una considerable altura. Mientras la cámara inicia un recorrido por encima de esta ciudad y empieza a acercarse a un edificio particular, aparece en pantalla el nombre de la ciudad y el estado (Phoenix, Arizona). Poco después aparece en pantalla el día y el mes ljueves 24 de agostol. Y finalmente, poco antes de que la cámara se detenga frente a una ventana del edificio, aparece sobre la pantalla la hora precisa l 4:23 pm). De esta manera, en pocos segundos hemos pasado de un PG (Plano General) de carácter temporal y espacial (la ciudad en el mes de agosto) a un PP (Primer Plano) temporal y espacial luna ventana precisa de un edificio particular, observado a las 4:23 pm del jueves 24).

El paso de un Plano General a un Primer Plano tiene un carácter didáctico, pues permite al espectador o lector identificar el lugar y el momento en el que ocurrirá la historia que se va a contar. Así, por ejemplo, las novelas decimonónicas de Balzac, Stendhal o Zola (Levin, 1974: 71), los cuentos de Poe (Meyers, 2000: 124) y las comedias románticas hollywoodenses (Echart, 2005: 87) se suelen iniciar mostrando una situación de carácter general len términos de tiempo y espaciol donde se ubica la historia que será narrada. Este principio es aplicable a cualquier clase de narración, como es el caso del cine documental clásico. Así, por ejemplo, Nanook el esquimal (John Flaherty, 1922) se inicia mostrando un mapa de la región donde vive la familia que será presentada. Y a continuación vemos salir del kayak a cada uno de los miembros de la familia de Nanook, incluyendo la esposa, los hijos, los abuelos y el perro que los acompaña en sus viajes.

Por su parte, el final clásico es epifánico, es decir, resuelve todos los enigmas narrativos planteados a lo largo de la historia. Este tipo de final suele ser sorpresivo y a la vez coherente con el resto de la historia. El final clásico es cerrado y único. Es un final necesario para resolver los enigmas planteados, y produce en el lector la sensación de Inevitabilidad en Retrospectiva, es decir, la sensación de que ese final era necesario e inevitable (Hills, 1987: 24). La Fórmula del Final Clásico es: ( $\mathrm{C}$ ( $\mathrm{f}$ ) $=\mathrm{V}$ (1) ). En esta fórmula se establece que el final (f) de carácter Clásico (C) equivale a una única (1) Verdad
(F). Por supuesto, se trata de una Verdad Ficcional, es decir, una verdad que depende del contexto de enunciación, en este caso de carácter narrativo. El final clásico corresponde a la solución del laberinto circular, es decir, el tipo de construcción len este caso, una construcción narratival donde sólo existe una única entrada y una única salida. En el final clásico se revela la verdad ficcional que da sentido y coherencia a la historia, y por eso este final puede ser considerado como el espacio de la revelación epistémica ficcional.

Aquí es conveniente recordar la propuesta de Borges, que sostiene que todo cuento (o toda película) siempre cuenta dos historias: una historia evidente y dominante a lo largo del texto y otra historia que está oculta y se revela sólo al final, de manera sorpresiva. El final clásico es sorpresivo en la medida que materializa la irrupción de la historia que ha sido recesiva y huésped a lo largo del relato, y que así se revela como la verdadera historia anfitriona y dominante (Borges en Zavala, 1993: 39). A partir de esta idea se puede afirmar que el Final Clásico es un final anafórico, es decir, un final en el que se retoman los elementos que fueron presentados a lo largo de la historia. Esto significa que este final adquiere sentido gracias a la lectura que se ha hecho del resto del texto.

Por último, al estudiar el Final Clásico se puede recordar la importancia que tiene lo que el músico John Cage llamó la Paradoja del Anfitrión. Esta paradoja se produce en una situación donde un elemento que originalmente es sólo un huésped -en este caso, la historia oculta- termina por revelarse como el verdadero anfitrión -en este caso, el elemento que contiene la verdad narrativa- (Ulmer, 1985: 136). Todos estos rasgos del final clásico se encuentran en Madame Bovary, en Don Quijote de La Mancha, en la Odisea, en el final de cada uno de los relatos contenidos en Boccaccio, en los cuentos policiacos y en la comedia musical: el final clásico resuelve todos los enigmas planteados a lo largo de la historia.

El final de North by Northwest (Intriga internacional, 1954) de Alfred Hitchcock es ejemplar porque en los últimos segundos del minuto final son resueltos todos los enigmas narrativos de las 5 historias planteadas en la historia: el protagonista salva su vida y la de su pareja; logra recuperar la micropelícula perdida; también recupera su propia identidad, materializada en su nombre lque ahora puede dar a su nueva esposa); se revela el bando al 
que pertenece la mujer de la que está enamorado, y accede a la madurez que significa estar casado. De esta manera, después de dos horas de contratiempos y el planteamiento de numerosos enigmas narrativos, de manera simultánea se resuelven la historia de aventuras; la historia política; la historia de espionaje; la historia edípica y la historia romántica.

Manhattan Transfer (1925), la prestigiosa novela de John Dos Passos, narra las historias de numerosos personajes que viven en Manhattan. En las últimas páginas de esta novela, todos ellos confluyen en la estación de trenes (Manhattan Transfer), lo cual ofrece la imagen de una ciudad diversa, llena de vida y con muchas historias dignas de ser contadas.

\section{Fórmulas de incoativa moderna}

El inicio moderno es aquel que se aleja de las reglas del inicio clásico. Mientras la narrativa clásica se apoya en la tradición, en cambio la narrativa moderna es casuística (cada caso es único), irrepetible (no puede ser reducida a una estrategia única) y depende de la visión de cada creador lcomo ocurre en el cine de autor). La Fórmula del Inicio Moderno es (M (i) $\neq C$ (i) ). Esta fórmula significa que el Inicio Moderno, $M(i)$, es equivalente a todo aquello que se distingue y se opone ( $\neq$ ) al Inicio Clásico, C (i).

El inicio moderno con frecuencia es expresionista (expresa alguna forma de angustia) y suele ser complejo, enigmático y confuso. El inicio moderno suele ser anafórico, lo que significa que lo más importante en la historia (con frecuencia el final) ocurrió antes de la secuencia inicial. En otras palabras, con frecuencia el inicio moderno tiene lugar in medias res, cuando la historia ya tiene un avance considerable o incluso ya terminó. Cuando la película empieza, generalmente ya ocurrió lo más importante de la historia.

El inicio moderno suele iniciarse mostrando un Primer Plano, es decir, algo muy particular que ocurre en un tiempo y un espacio indeterminados, lo cual plantea un enigma que no siempre se resuelve a lo largo ni al final del relato. ¿Dónde ocurre lo que vemos en pantalla? ¿Quiénes son los personajes y por qué están ahí? ¿Cómo se llegó a esta situación particular? Éstas y otras preguntas son inevitables al ver un Inicio Moderno, y si la narración tiene un Final
Moderno ninguna de estas preguntas será respondida en ningún momento. Por eso cada narración moderna es distinta de cualquier otra.

La metamorfosis de Franz Kafka tiene un inicio moderno, pues cuando Gregorio Samsa amanece convertido en un insecto (desde la perspectiva del narrador), lo más importante ya ocurrió, es decir, todo aquello que lo llevó a esta situación deplorable. El primer capítulo de Ulysses de James Joyce es enigmático, confuso y complejo, y el resto de la novela acentuará esos rasgos. Las primeras líneas de En busca del tiempo perdido de Marcel Proust se detienen en el recuerdo de una experiencia muy particular en la vida del narrador lla experiencia de comer un cierto tipo de pan), lo que dará pie para iniciar la narración sobre los momentos más memorables de su vida personal.

El final moderno es abierto, indeterminado y múltiple. Deja a la imaginación del lector la posible conclusión o desenlace narrativo. Esta indeterminación pone el énfasis ya no en el texto y su sentido epistémico o moral, sino en el lector y su experiencia personal y de lectura. La Fórmula del Final Moderno es $\left(M(f)=\sum(f)\right)$, que significa que el Final Moderno, M (f) contiene más de un final, $\Sigma(f)$, donde el signo $\sum$ debe leerse como muchos o más de uno. El Final Moderno es un Final Abierto, y por lo tanto también puede describirse de esta otra forma: $\left(M(f)=\sum(V(n))\right)$, lo que significa que el final moderno, $M(f)$, contiene una Multiplicación ( $\sum$ ) de Verdades Posibles, donde (n) equivale a cualquier número entero. En otras palabras, el final moderno es abierto a las interpretaciones de cada lector: es un final indeterminado, ambiguo, abierto, incompleto.

El final moderno corresponde a la estructura del laberinto arbóreo, es decir, el tipo de construcción arquitectónica o textual donde hay una única entrada (el planteamiento de determinados enigmas narrativos) y múltiples salidas o soluciones válidas, ya sean simultáneas o alternativas. Es un final catafórico, que por lo tanto propicia que el lector efectúe una relectura irónica del texto.

La dama del perrito es el cuento que el escritor ruso Vladimir Nabokov considera como paradigmático de la literatura moderna. En el Curso de literatura rusa, que contiene las notas del curso que impartió durante varios años en la Universidad de Princeton, se explica en qué consiste la modernidad de este cuento. Escrito en la última década del 
siglo XIX, este cuento tiene un final indeterminado. Los protagonistas están felizmente casados con sus respectivas parejas, pero se conocen y se enamoran, y tienen encuentros furtivos durante varios años. En el párrafo final del cuento ellos conversan sobre lo que deben hacer con sus vidas. Pero nunca sabremos a ciencia cierta qué decisión deciden tomar. Así que será el lector (si así lo decide) quien concluya la historia en su imaginación. A este tipo de final se le conoce con el nombre de final abierto.

\section{Fórmulas de incoativa posmoderna}

El inicio posmoderno se produce por la yuxtaposición de los rasgos del inicio clásico y el inicio moderno. Esta naturaleza paradójica genera dos mecanismos característicos de la estética posmoderna, a saber, simultaneidades y simulacros (tanto de lo clásico como de lo moderno). La Fórmula del Inicio Posmoderno es (PM (i) $=\sum(C(i)+M(i))$ ), lo cual significa que en el Inicio Posmoderno, PM (i), coexisten ( $\sum$ ) un inicio clásico, C (i), y un inicio moderno, $M$ (i). El inicio posmoderno es al mismo tiempo clásico y moderno; cerrado y abierto; contiene rasgos tradicionales y rasgos experimentales; resuelve los enigmas narrativos y al mismo tiempo plantea nuevos enigmas. Posee, como toda la estética posmoderna, un inicio lúdico, paradójico y auto-referencial.

El inicio posmoderno puede ser leído como un inicio clásico o como un inicio moderno, ya sea de manera alternativa o de manera simultánea. Esto significa que puede ser leído como convencional y al mismo tiempo como alegórico, es decir, al mismo tiempo didáctico y enigmático, convencional e irrepetible. El inicio posmoderno contiene rasgos identificables como clásicos, pero es suficientemente irónico y ambiguo como para que el espectador juegue con su imaginación.

El inicio posmoderno suele ser híbrido y metaficcional, tematizando su propia naturaleza incoativa y utilizando recursos narrativos de tradiciones antagónicas. Por ejemplo, los primeros siete minutos de la película chicana Zoot Suit (Fiebre latina, 1982) contienen imágenes fijas y en movimiento; imágenes en color y otras en blanco y negro; este inicio alude al pasado histórico y al presente de los personajes; establece una distinción entre ver y ser visto llos espectadores de esta película vemos a unos espectadores de teatro llegando al inicio del espectáculo y tomando sus asientos, pero también disfrutamos del espectáculo que ellos observan desde sus butacas); entremezcla elementos de cine documental y elementos del cine de ficción; yuxtapone estrategias del cine musical más espectacular y estrategias de reflexividad propias del teatro brechtiano de la vanguardia artística y política.

La novela El nombre de la rosa (1980) de Umberto Eco se inicia con el relato del narrador apócrifo que revela cómo fue hallado el manuscrito que ahora será leído. Es decir, se tematiza (se convierte en el tema de la narración) el hecho de estar leyendo esta novela. Esta novela tiene un inicio metaficcional. En el primer párrafo de la novela italiana $S i$ una noche de invierno un viajero, de Italo Calvino, se tematiza el hecho de leer ese primer párrafo:

Estás a punto de empezar a leer la nueva novela de Italo Calvino, Si una noche de invierno un viajero. Relájate. Recógete. Aleja de ti cualquier otra idea. Deja que el mundo que te rodea se esfume en lo indistinto. La puerta es mejor cerrarla; al otro lado siempre está la televisión encendida. Dilo en seguida a los demás: “¡No, no quiero ver la televisión!”. Alza la voz, si no te oyen: “iEstoy leyendo! ¡No quiero que me molesten!”. Quizá no te han oído, con todo el estruendo; dilo más fuerte: “¡Estoy empezando a leer la nueva novela de Italo Calvino!". O no lo digas si no quieres; esperemos que te dejen en paz. (Calvino, 1980: 9).

En la primera línea de la novela Gringo viejo (1986) de Carlos Fuentes se lee: "Ella se sienta sola y recuerda”. Esta afirmación es simultáneamente anafórica y catafórica. Es catafórica les decir, anuncia lo que siguel porque la mujer se sienta a recordar, y esos recuerdos serán la materia del resto de la novela. Pero al mismo tiempo, esta primera línea de la novela también es anafórica les decir, remite a algo anterior), porque todo eso que está a punto de ser contado ya ocurrió antes, y ahora forma parte de la memoria.

La secuencia inicial de la película Amélie (2001) presenta un inicio posmoderno, pues es al mismo tiempo un Primer Plano y un Plano General. Es un Primer Plano de carácter cronológico al tratar sobre el preciso instante en el que ocurre la concepción de Amélie. Y es un Plano General de carácter espacial al mostrar algunos de los acontecimientos que están ocurriendo en el universo en ese preciso instante luna mosca es aplastada por un auto; unas 
copas bailan movidas por el viento sin que nadie las observe; un hombre borra de su directorio a un amigo que falleció recientemente).

Los primeros dos minutos de La mujer de al lado (1981) de Francois Truffaut están construidos como un sistema de simulacros: un simulacro de inicio clásico ("Se podría decir que esta historia se inició hace diez años, pero no: se inició hace seis meses"); un simulacro de inicio moderno ("La ambulancia llegó demasiado tarde, pues venía desde Champfleury"); un simulacro de identidad ("Si ustedes creen que yo soy tenista, se equivocan; que la cámara se aleje para que puedan ver bien"); un simulacro de espontaneidad ("Vamos a sentarnos allá; no, mejor aquí"), y un simulacro de registro (“La familia está posando frente a su casa para un fotógrafo que nunca llegó").

El final posmoderno es paradójico e irónico, pues contiene, como simulacros, la coexistencia de un final verdadero y único (clásico) y un final abierto y múltiple (moderno). El sentido último de un final posmoderno depende de la interpretación que cada lector haga de él y puede cambiar en cada lectura particular. La Fórmula del Final Posmoderno es $\left(P M(f)=\sum(C(f), M(f))\right)$. Esto significa que el Final Posmoderno, PM (f), es la suma ( $\sum$ ) de un Final Clásico, C (f) y un Final Moderno, M (f). A su vez, el Final Posmoderno es un Final Simultáneamente Abierto y Cerrado, es decir, $P M(f)=\sum(V(1), V(n)$ ), donde hay simultáneamente Una Verdad Única, V (1), y Muchas Verdades Posibles, V (n).

El final posmoderno corresponde al laberinto rizomático o reticular, donde puede haber simultáneamente una y muchas salidas (como en una red). Este final suele ser paródico, y pone en juego una intertextualidad genérica. Esto significa que el final posmoderno suele poner en juego alusiones irónicas a las reglas de los géneros narrativos clásicos. El cuento "El jardín de senderos que se bifurcan" (1944) de Jorge Luis Borges tiene un final que concluye la historia de espionaje, pero al mismo tiempo deja abierta la argumentación filosófica acerca de la naturaleza real o imaginaria del tiempo en la historia colectiva. "Continuidad de los parques" (1959) de Julio Cortázar es el mejor ejemplo de final posmoderno, pues mientras este final queda abierto (ya que no está escrito en el cuento), al mismo tiempo cada lector, inevitablemente, imagina un desenlace para la historia (Zavala, 2007: 299-311).

La película chicana Zoot Suit (Fiebre latina, 1982) es la reconstrucción ficcionalizada de un hecho histórico. En ella se termina reconstruyendo lo que ocurrió en la vida real del protagonista. Pero después de escuchar ese final feliz acompañado por música igualmente gloriosa, el personaje que representa el Espíritu de La Raza le dice a Henry Reyna: “¡Qué bien! Happy Ending y todo. Pero la vida no es así, Hank". Cuando este personaje simbólico chasquea los dedos conocemos distintas versiones de lo que pudo haber ocurrido en la vida de este chicano, desde la perspectiva de la ley estadounidense; la militancia socialista; la lucha por los derechos humanos, y la novia que lo esperó durante varios años mientras él cumplía su condena en la cárcel (Zavala, 1993: 66-68).

\section{Conclusión}

El hecho de contar con un sistema de fórmulas narrativas puede contribuir al estudio de terrenos específicos de la narratología contemporánea, tales como: la teoría de la adaptación, la teoría de la traducción semiótica, la teoría de los géneros, y la incipiente teoría de la narratología médica. En la teoría de la adaptación, la utilidad de las fórmulas narrativas consiste en la posibilidad de comparar la naturaleza incoativa y terminativa del texto literario original y el texto fílmico, precisando así la manera como las condiciones de producción cinematográfica contribuyen a preservar o modificar la naturaleza original del material literario. En la teoría de la traducción semiótica, las fórmulas pueden ser utilizadas para estudiar las condiciones en las que se trabaja dentro de un mismo sistema semiótico, como el cine len los casos de remake, retake, homenaje o parodial o al estudiar la traducción de un sistema semiótico a otro (como al pasar del formato literario al cinematográfico).

En la teoría de los géneros, las fórmulas narrativas encuentran su utilidad al precisar los recursos utilizados al pasar de un sistema narrativo (como la prensa diaria o la narrativa gráfical a otro sistema narrativo (como el documental o la novela). En la narratología médica luna variante instrumental de la narratología), las fórmulas narrativas pueden estar al servicio de una tipología de recursos que son útiles para apoyar el tratamiento de distintos casos con necesidades particulares.

Por otra parte, la existencia de un sistema de fór- 
mulas narrativas como el presentado en este artículo puede contribuir a la sistematización de los talleres para la formación de narradores de historias (en cine o literatura), mostrando así la pertinencia de los modelos teóricos en la formación de los creadores de historias. Las fórmulas narrativas presentadas se desprenden de la observación de distintas tradiciones teóricas y del estudio de la producción textual canónica en cine y literatura. Con estas propuestas queda abierto el camino para seguir explorando este terreno relativamente reciente de la narratología contemporánea.

\section{Referencias bibliográficas}

Adama, J.M. \& Lorda, C. (1999). Lingüística de los textos narrativos. Barcelona: Ariel.

Barthes, R. (1996). "Introducción al análisis estructural de los relatos" en VV. AA.: Análisis estructural del relato, pp. 7-38. México, Coyoacán.

Barthes, R. (1980). S/Z. México, Siglo XXI Editores.

Borges, J. L. (1922 [1944]). “El jardín de senderos que se bifurcan”, en Obras completas. Buenos Aires: Emecé.

Borges, J. L. (1993) “Prólogo" a Los nombres de la muerte (1964) de María Esther Vázquez, en Prólogos con un prólogo de prólogos. Buenos Aires: Torres Agüeiro editores, 1975. En Zavala, L. (comp.), Teorías del cuento. México: UNAM.

Calvino, I. (1980). Si una noche de invierno un viajero. Barcelona: Bruguera.

Cervantes, M. (2012 [1964]). Don Quijote de La Mancha. Guanajuato, Museo Iconográfico del Quijote.

Cortázar, J. (1996 [1964]). “Continuidad de los parques”, en Cuentos Completos, vol. 1 (1945-1966), pp. 291-292. México: Alfaguara.

Courtés, J. (1980). Introducción a la semiótica narrativa y discursiva. Metodología y aplicación. Buenos Aires: Hachette.

Echart, P. (2005). La comedia romántica del Hollywood de los años 30 y 40. Madrid: Cátedra.

Eco, U. (1983). "Cuernos, cascos y zapatos: Algunas hipótesis sobre tres tipos de abducción" en Eco, U. y Sebeok, T. (ed.), El signo de los tres. Dupin, Holmes, Peirce, pp. 265-293. Barcelona: Lumen.

Eco, U. (1984). El nombre de la rosa. México: Lumen.

Flaubert, G. (1986). Madame Bovary. Madrid: Cátedra.

Fludernik, M. (2009). An Introduction to Narratology. London: Routledge.

Fuentes, C. (1984). Gringo viejo. México: Fondo de Cultura Económica.

Gaudreault, A. \& Jost, F. (1995). El relato cinematográfico. Cine y narratología.

Barcelona: Paidós. 
Genette, G. (1980). Narrative Discourse. An Essay in Method. Ithaca: Cornell University Press.

Greimas, A. J. \& Courtés, J. (1991). Semiótica. Diccionario razonado de la teoría del lenguaje. Madrid: Gredos.

Herman, L. \& Vervaeck, B. (2001). Handbook of Narrative Analysis. Lincoln and London: University of Nebraska Press.

Hills, R. (1987). Writing in General and the Short Story in Particular. Boston: Houghton Mifflin Company.

Hydén, L. (2008). “Medicine and Narrative”, en Herman, D. et al, 293-297

Keen, S. (2003). Narrative Form. New York: Palgrave.

Kermode, F. (1983). El sentido de un final. Estudios sobre teoría de la ficción. Barcelona: Gedisa.

Klein, J. T. (1996). Crossing Boundaries. Knowledge, Disciplinarities, and Interdisciplinarities. Charlottesville: University Press of Virginia.

Kunz, M. (1997). El final de la novela. Madrid: Gredos.

Levin, H. (1974). El realismo francés. Stendhal, Balzac, Proust, Flaubert, Zola, Proust. Barcelona: Laia.

Martínez, M. \& Schefel, M. (2011). Introducción a la narratología. Hacia un modelo analítico-descriptivo de la narración ficcional. Buenos Aires: Las Cuarenta.

MacDowell, J. (2014). Happy Endings in Hollywood Cinema. Cliché, Convention and the Final Couple. Edinburgh University Press.

Meyers, J. (2000). Edgar Allan Poe. His Life and Legacy. New York: First Cooper Square Press.

Nabokov, V. (1984). “La dama del perrito”, en Curso de Literatura Rusa, pp. 378-386. Barcelona: Bruguera.

Neupert, R. (1995). The End. Narration and Closure in the Cinema. Detroit: Wayne State University.

Propp, V. (1972). Morfología del cuento. Madrid: Fundamentos.

Reis, C. \& Lopes, A. (1996). Diccionario de narratología. Salamanca, Ediciones Colegio de España.

Sebeok, T. y Umiker-Sebeok, J. (1987). Sherlock Holmes y Charles S. Peirce. El método de la investigación. Barcelona: Paidós.

Shklovski, V. (1970). “El arte como artificio” en VV.AA, Teoría de la literatura de los formalistas rusos, pp. 55-70. México: Siglo XXI Editores.

Tomachevski, B. (1982). Teoría de la literatura. Madrid: Akal.

Ulmer, G. (1985). “El objeto de la poscrítica” en Hal Foster (coord.), La

Posmodernidad, pp. 125-164. Barcelona: Kairós.

Valles Mingo, R. (2009). La narratología en el siglo XX. Un panorama teórico y temático. México: UNAM.

Van den Oever, A. (2013). Ostrannenie. On "Strangeness" and the Moving Image. The History, Reception, and Relevance of a Concept (ed.). Amsterdam: Amsterdam University Press. 
Verstratten, P. (2009). Film Narratology. Toronto: University of Toronto Press.

Wollen, P. (1982). Readings and Writings. Semiotic Counter-Strategies. London: Verso.

Wright, W. (1976). Sixguns and Society. A Structural Analysis of the Western. Berkeley: The University of California.

Zavala, L. (1993). "La metaficción dramatizada en Fiebre latina" en Elementos del discurso cinematográfico. México, UAM Xochimilco, 66-68.

Zavala, L. (2007). “Continuaciones para 'Continuidad de los parques' " en Ironías de la ficción y la metaficción en cine y literatura. México, Universidad Autónoma de la Ciudad de México, 299-311.

Zavala, L. (1995). “El cuento policiaco”, en La escritura del cuento (ed.). México: Dirección de Literatura, Universidad Nacional Autónoma de México, 309-428.

\section{Filmografía}

Flaherty, Robert. (1922). Nanook of the North. EEUU.

Hitchcock, Alfred. (1929). Blackmail (Juego sucio). GB

Hitchcock, Alfred. (1936). Sabotage (Sabotaje). GB.

Hitchcock, Alfred. (1948) Rope (La soga). EEUU.

Hitchcock, Alfred. (1951). Strangers in a Train (Pacto siniestro). EEUU.

Hitchcock, Alfred. (1959). North by Northwest (Intriga internacional). EEUU.

Hitchcock, Alfred. (1960). Psycho (Psicosis). EEUU.

Hitchcock, Alfred. (1964). Marnie. EEUU.

Jeunet, Jean-Pierre. (2001). Le fabuleux destin d'Amélie Poulain. Francia.

Taviani, Paolo \& Vittorio. (2015). Maraviglioso Boccaccio. Italia.

Triana, Jorge Alí. (1996). Oedipo alcalde. Colombia-México-España-Cuba.

Truffaut, Francois. (1981). La femme d'a cote (La mujer de al lado). Francia.

Valdez, Luis. (1981). Zoot Suit (Fiebre latina). EEUU.

Vertov, Dziga. (1929). El hombre de la cámara. URSS.

Young, Terence. (1967). Wait Until Dark (Espera la obscuridad). EEUU.

\section{Sobre el autor}

\section{Lauro Zavala}

Doctor en literatura hispánica por El Colegio de México. Investigador en UAM Xochimilco y profesor invitado en UNAM y New York University. Autor de varios libros sobre teoría literaria y cinematográfica. Sus trabajos más recientes son: Una antología de cien años de literatura mexicana en traducción a lenguas indígenas (Conaculta, 2013) y Semiótica preliminar. Ensayos y conjeturas (FOEM, 2014).

\section{Cómo citar:}

Zavala, L. (2016). "Las fórmulas narrativas en cine y literatura: una propuesta paradigmática”. Comunicación y Medios, 25 (34), 70 - 81. 